\title{
Conformational States and Kinetics of the Calcium Binding Domain of NADPH Oxidase 5
}

\author{
Chin-Chuan Wei*, ${ }^{1}$, Nicole Motl ${ }^{1}$, Kelli Levek ${ }^{1}$, Liu Qi Chen ${ }^{1}$, Ya-Ping Yang ${ }^{2}$, Tremylla Johnson ${ }^{1}$, \\ Lindsey Hamilton ${ }^{1}$ and Dennis J. Stuehr ${ }^{2}$ \\ ${ }^{1}$ Department of Chemistry, Southern Illinois University Edwardsville, Edwardsville, IL 62026, USA
${ }^{2}$ Department of Pathobiology, the Lerner Research Institute, Cleveland Clinic Foundation, Cleveland, OH 44195, USA
}

\begin{abstract}
Superoxide generated by human NADPH oxidase 5 (NOX5) is of growing importance for various physiological and pathological processes. The activity of NOX5 appears to be regulated by a self-contained $\mathrm{Ca}^{2+}$ binding domain $(\mathrm{CaBD})$. Recently Bánfi et al. suggest that the conformational change of $\mathrm{CaBD}$ upon $\mathrm{Ca}^{2+}$ binding is essential for domain-domain interaction and superoxide production. The authors studied its structural change using intrinsic Trp fluorescence and hydrophobic dye binding; however, their conformational study was not thorough and the kinetics of metal binding was not demonstrated. Here we generated the recombinant $\mathrm{CaBD}$ and an $\mathrm{E} 99 \mathrm{Q} / \mathrm{E} 143 \mathrm{Q}$ mutant to characterize them using fluorescence spectroscopy. $\mathrm{Ca}^{2+}$ binding to $\mathrm{CaBD}$ induces a conformational change that exposes hydrophobic patches and increases the quenching accessibilities of its Trp residues and AEDANS at Cys107. The circular dichroism spectra indicated no significant changes in the secondary structures of $\mathrm{CaBD}$ upon metal binding. Stopped-flow spectrometry revealed a fast $\mathrm{Ca}^{2+}$ dissociation from the $\mathrm{N}$-terminal half, followed by a slow $\mathrm{Ca}^{2+}$ dissociation from the Cterminal half. Combined with a chemical stability study, we concluded that the C-terminal half of $\mathrm{CaBD}$ has a higher $\mathrm{Ca}^{2+}$ binding affinity, a higher chemical stability, and a slow $\mathrm{Ca}^{2+}$ dissociation. The $\mathrm{Mg}^{2+}$-bound $\mathrm{CaBD}$ was also investigated and the results indicate that its structure is similar to the apo form. The rate of $\mathrm{Mg}^{2+}$ dissociation was close to that of $\mathrm{Ca}^{2+}$ dissociation. Our data suggest that the $\mathrm{N}$ - and C-terminal halves of $\mathrm{CaBD}$ are not completely structurally independent.
\end{abstract}

Keywords: NADPH oxidase, fluorescence, circular dichroism, calcium binding, kinetics.

\section{INTRODUCTION}

Reactive oxygen species (ROS) such as nitric oxide, superoxide, and hydrogen peroxide have received much attention recently due to their implications in physiology and pathophysiology [1]. Superoxide is primarily generated by the enzyme family of NADPH oxidases (NOXs), and there are several homologous enzymes identified so far, including NOX1, NOX2, NOX3, NOX4, NOX5, and dual oxidase [2, $3]$. Among them, NOX2 is well known for its pathogenkilling ability in phagocytes, in which a large amount of superoxide is generated through the NOX2 multienzymatic system [4]. While such a large amount of superoxide is essential in phagocytic cells, superoxide generated from other non-phagocytic cells has been implicated in intracellular signaling leading to altered gene expression and protein biosynthesis, apoptosis, migration, hypertrophy, kinase activation, oxygen sensing, bone resorption, and extracellular matrix modification [5]. Accordingly, deficiency or overproduction of superoxide has been demonstrated to lead to pathological problems, as well as neurological, cardiovascular, or renal diseases [6-8].

The exact biological functions and superoxide-generating mechanisms of non-phagocytic NOXs are still unclear. Like the NOX2 system, NOX1 and NOX3 require accessory

*Address correspondence to this author at the Department of Chemistry, Southern Illinois University Edwardsville, Edwardsville, IL 62026-1652, USA; Tel: 618-650-2454; Fax: 618-650-3556; E-mail: cwei@ siue.edu proteins such as NOXA1, $447^{\text {phox }}$, and/or $\mathrm{p} 67^{\text {phox }}$ to form a multi-enzyme complex for superoxide production [2]. Interestingly, the NOX5 activity is regulated by $\mathrm{Ca}^{2+}$ flux, which was demonstrated in vivo [9] and in vitro [10]. NOX5 was detected in all fatal tissue, and is expressed in adult spleens, testis, ovary, placenta, pancreas $[3,9]$, sperm, and while blood cells [11]. NOX5 consists of a gp91 ${ }^{\text {phox }}$ homologous flavoprotein domain that binds FAD and NADPH, a heme-binding transmembrane domain, and a $\mathrm{Ca}^{2+}$-binding domain $(\mathrm{CaBD})$. Based on the model of NOX2 [12], the hypothesized mechanism for NOX5 is that $\mathrm{Ca}^{2+}$ binding causes a conformational change on $\mathrm{CaBD}$, exposing hydrophobic patches, and leading to interactions between the $\mathrm{CaBD}$ and flavoprotein domains, which allows for electron transfer from NADPH to molecular oxygen. The physical interaction between the CaBD and flavoprotein domains has been demonstrated by pull-down method [10]. Based on this model, NOX5 contains all essential components for superoxide production. However, the high concentration of $\mathrm{Ca}^{2+}$, approximately $40 \mu \mathrm{M}$, needed to saturate $\mathrm{CaBD}$ and activate NOX5 superoxide production in vitro makes such $\mathrm{Ca}^{2+}$-activation mechanism nonexclusive because it is unclear whether such concentration can be met in stimulated cells. Indeed, recent studies indicate that the NOX5's calcium sensitivity is enhanced by the interaction with calmodulin (CaM) [13] and by a phosphorylation mechanism [14]. Information on how $\mathrm{Ca}^{2+}$ and other factors influence the electron transfer within NOX5 is essential for understanding its superoxide-producing mechanism. 
CaBD contains four $\mathrm{Ca}^{2+}$ binding sites, forming two tandem pairs with one non-canonical and three canonical EFhand motifs. Its $\mathrm{Ca}^{2+}$ binding has been investigated by flow dialysis and the results indicate that its $\mathrm{N}$-terminal half containing the $1^{\text {st }}$ and $2^{\text {nd }}$ EF-hand motifs has a low $\mathrm{Ca}^{2+}$ binding affinity $\left(K_{d}=15-20 \mu M\right)$, while the C-terminal half containing the $3^{\text {rd }}$ and $4^{\text {th }}$ EF-hand motifs has a high $\mathrm{Ca}^{2+}$ binding affinity $\left(\mathrm{K}_{\mathrm{d}}=3.75-3.80 \mu \mathrm{M}\right) \quad$ [10]. The conformational change of $\mathrm{CaBD}$ induced by $\mathrm{Ca}^{2+}$ binding appears to be very important for it to interact with the NOX5's flavoprotein domain. Previously, this conformational change was monitored by intrinsic tryptophan (Trp) fluorescence and 2,6-p-toluidinonaphthalene sulfonate (TNS) binding for hydrophobic content [10]. However, neither an examination of the conformational change of $\mathrm{CaBD}$ upon $\mathrm{Mg}^{2+}$ binding, nor an investigation of kinetics about metal ion association and dissociation for $\mathrm{CaBD}$ has been reported. Here we utilized techniques of fluorescence quenching, 8-anilino-1naphthalene sulfonic acid (ANS) hydrophobic binding, and chemical-induced unfolding monitored by intrinsic and extrinsic fluorescence to characterize CaBD. Furthermore, the secondary structure of $\mathrm{CaBD}$ was determined by $\mathrm{CD}$ spectroscopy, and the kinetics of metal dissociation from CaBD was determined using stopped-flow spectroscopy.

\section{MATERIALS AND METHODS}

\section{Reagents}

All chemicals were purchased from Sigma-Aldrich (St. Louis, MO) and Fisher Scientific (Pittsburgh, PA), and used without further purification. All buffers used in the protein purification and the subsequent spectroscopic characterization were rendered " $\mathrm{Ca}^{2+}$-free" by treatment with Chelex100 (Bio-Rad Laboratories, Hercules, CA). The spectroscopic measurements were performed at least three times using at least three different protein batches and were reproducible.

\section{Plasmid Constructions}

The pLW vector, a generous gift from Dr. Lucy Waskell at the University of Michigan, was digested with Nco I and Xho I, and a phosphorylated double stranded oligonucleotide (5'-CATGGCGCATCATCACCATCACCATGCGGTAC

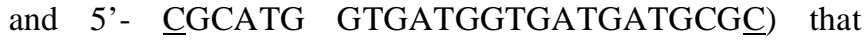
encodes peptide sequence MAHHHHHAV and contains Nco I and Kpn I compatible sites (underlined), flanking 5' and 3' ends, was ligated to the digested $\mathrm{pLW}$ vector to create a linear $\mathrm{pLW}-\mathrm{His}_{6}$ vector containing Kpn I and Xho I cloning sites. The cDNA encoding human NOX5 $\beta$ was a generous gift from Dr. Botond Bánfi at the University of Iowa. The CaBD domain (residues 1-184) was amplified by polymerase chain reaction (PCR) with the primers: 5'-GACTGGTACCG ATGAGTGCCGAGGAG) and 5'-CGCACTCGAGTTAGG CGCGGGTCAGCTG. The forward and reverse primers introduced two restriction sites (underlined) for Kpn I and Xho I sites on both ends and a stop codon in the 3' end. The PCR product was subcloned into the above $\mathrm{pLW}-\mathrm{His}_{6}$ vector to create the plasmid $\mathrm{pLW}-\mathrm{His}_{6} \mathrm{CaBD}$. The recombinant protein was constructed in such way that it contains an additional eleven amino acids, MAHHHHHHAVP, on its N terminus. The plasmid containing the mutant E99Q/E143Q was generated using a QuickChange Site-Directed
Mutagenesis Kit (Stratagene, La Jolla, CA). Two sequential site-directed mutations were performed by first generating the single mutation $\mathrm{E} 99 \mathrm{Q}$, and then $\mathrm{E} 99 \mathrm{Q} / \mathrm{E} 143 \mathrm{Q}$. The clones were sequenced to confirm the mutations and the oligonucleotide primers were synthesized by Integrated DNA Technologies (Coralville, IA).

\section{Recombinant Protein Expression and Purification}

The plasmids $\mathrm{pLW}-\mathrm{His}_{6} \mathrm{CaBD}$ or $\mathrm{pLW}-\mathrm{His}_{6} \mathrm{E} 99 \mathrm{Q} / \mathrm{E} 143 \mathrm{Q}$ were introduced into BL21(DE3) E. coli cells. Cells were grown in Luria-Bertani (LB) medium to $\mathrm{OD}_{600} 0.5-0.7$, and the expression was induced by the addition of $1 \mathrm{mM}$ isopropyl- $\beta$-D-thiogalactopyranoside (IPTG) at $37{ }^{\circ} \mathrm{C}$ for $4 \mathrm{~h}$. All of the following purification steps were performed at $4{ }^{\circ} \mathrm{C}$. The histidine-tagged recombinant proteins were first purified with a $\mathrm{Ni}^{2+}$-chelating Probond column (Invitrogen Carlsbad, CA). Briefly, after harvest cells were resuspended in a buffer containing $50 \mathrm{mM}$ Tris, $\mathrm{pH} 7.5,0.5 \mathrm{M} \mathrm{NaCl}, 10$ $\mathrm{mM}$ Imidazole (Buffer A) followed by homogenization and centrifugation. The resulting supernatant was loaded on a Probond column equilibrated with Buffer A. The column was washed with the same buffer until $\mathrm{OD}_{280}$ reached baseline. The target protein was eluted with Buffer A containing $300 \mathrm{mM}$ imidazole. Protein was further purified with a phenyl-sepharose column (GE Healthcare BioSciences, Piscataway, NJ) as previously reported for $\mathrm{CaM}$ [15]. The purified proteins were then buffer-exchanged in an Amicon Ultra centrifugal filter device (5,000 Da MWCO, Millipore, Bellerica, MA) with a buffer containing $50 \mathrm{mM}$ Tris, $0.125 \mathrm{M} \mathrm{NaCl}, 5 \%$ glycerol, $1 \mu \mathrm{M}$ EDTA, pH 7.5 and stored at $-80^{\circ} \mathrm{C}$ until use. The protein purity was estimated > $95 \%$ based on density profiles measured using UN-SCANIT software (Silk Scientific, Inc, Orem, UT).

\section{Preparation of AEDANS-Labeled CaBD and E99Q/ E143Q}

Approximately $100 \mu \mathrm{M}$ purified CaBD or E99Q/E143Q in $50 \mathrm{mM}$ EPPS, pH 7.5 was incubated with $2 \mathrm{mM} 5-((((2-$ iodoacetyl)amino)ethyl)amino)naphthalene-1-sulfonic acid (IAEDANS, Invitrogen) in the presence of $1 \mathrm{mM} \mathrm{Ca}^{2+}$ at $4{ }^{\circ} \mathrm{C}$ overnight in the dark. Iodoacetamide was added to the reaction mixture (final concentration was $1 \mathrm{mM}$ ) to quench the reaction. The free dye and quencher molecules were removed by passing the mixture through a $\mathrm{Ni}^{2+}$-chelating column, and the AEDANS-labeled protein was recovered by eluting with a $0.3 \mathrm{M}$ imidazole solution. The stoichiometry of the labeling was determined to be $0.93 \pm 0.11$ based on the protein assay kit (Bio-Rad Laboratories) for proteins and the absorption coefficient $\left(5,700 \mathrm{~cm}^{-1} \mathrm{M}^{-1}\right)$ for IAEDANS.

\section{Spectroscopic Measurements}

Absorption measurements were carried out using a Cary$3 \mathrm{UV} /$ vis double-beam spectrometer (Varian, Inc., Lake Forest, CA). The fluorescence spectra were recorded on a FluoroMax-3P (Horiba John Yvon, Inc., Edison, NJ) equipped with excitation/emission polarizers and a temperature control unit. In all cases, the fluorescence spectra were typically obtained using $2-10 \mu \mathrm{M}$ protein with the excitation wavelengths at 295, 340, and $350 \mathrm{~nm}$ for Trp, AEDANS, and ANS fluorescence, respectively, at $20{ }^{\circ} \mathrm{C}$. The window widths of 2 and $5 \mathrm{~nm}$ for the entrance and exit slits were chosen to eliminate photobleaching. All reported 
spectra were corrected for buffer effects, dilution factors, and any wavelength-dependent response for the fluorometer.

\section{Stern-Volmer Quenching}

Intrinsic and extrinsic fluorescence quenching experiments were carried out at $20{ }^{\circ} \mathrm{C}$ by adding a stock solution of $6 \mathrm{M}$ acrylamide, which was determined using the absorbance coefficient $\varepsilon_{295}=2.5 \mathrm{M}^{-1} \mathrm{~cm}^{-1}$, to the sample solution containing $4-10 \mu \mathrm{M}$ protein and $50 \mathrm{mM}$ Tris, 0.125 $\mathrm{M} \mathrm{NaCl}, \mathrm{pH}$ 7.5. The following Stern-Volmer quenching equation was used for fitting

$\mathrm{F}_{\mathrm{o}} / \mathrm{F}=\left(1+\mathrm{K}_{\mathrm{sv}}[\mathrm{Q}]\right)$

eq. 1

where $\mathrm{F}$ and $\mathrm{F}_{\mathrm{o}}$ are the fluorescence intensities at a given concentration of quencher and in the absence of quencher, respectively, $\mathrm{K}_{\mathrm{sv}}$ is the dynamic or collisional quenching constant, and [Q] is the concentration of added quencher.

\section{Far-UV Circular Dichroism (CD)}

The CD spectra were recorded using a JASCO J-715 instrument (JASCO Corporation, Japan) equipped with a temperature control unit. CD spectra were recorded using a cylindrical $0.1 \mathrm{~cm}$ path quartz curve and were shown as the average of 3 scans using a spectra bandwidth of $1.0 \mathrm{~nm}$. In all measurements, $0.1 \mathrm{mg} / \mathrm{ml}$ proteins in $10 \mathrm{mM}$ Tris, $\mathrm{pH} 7.5$ with $1 \mathrm{mM} \mathrm{Ca}^{2+}, 10 \mathrm{mM} \mathrm{Mg}{ }^{2+}$, or $0.5 \mathrm{mM}$ EDTA were scanned from $190 \mathrm{~nm}$ to $260 \mathrm{~nm}$.

\section{Kinetics of Metal Dissociation}

The kinetics was measured using the FluroMax-3P with a stopped-flow accessory SFA-20 (Tgk Scientific, Bradfordon-Avon, UK). To determine the calcium dissociation rate constant, a solution containing 5 to $10 \mu \mathrm{M}$ unlabeled protein (or 2 to $5 \mu \mathrm{M}$ labeled protein) and $100 \mu \mathrm{M} \mathrm{Ca}^{2+}$ (or $2 \mathrm{mM}$ $\mathrm{Mg}^{2+}$ plus $1 \mathrm{mM}$ EGTA) was rapid-mixed with a solution containing EDTA ranging from 10 to $20 \mathrm{mM}$ EDTA at $20{ }^{\circ} \mathrm{C}$. $\mathrm{Ca}^{2+}$ or $\mathrm{Mg}^{2+}$ dissociation was monitored by fluorescence decay. Six to eight injections were averaged to generate the final traces shown in Fig. (5). The integration time and time interval were 2 and $5 \mathrm{~ms}$, respectively. Since the data acquisition for our instrument is triggered after the stopped syringe meets the stop block, the points collected in the original data set are tens of ms later after mixing. The following single-exponential decay equation was used to fit the data

$\mathrm{Y}=\mathrm{Y}_{\mathrm{o}}+\mathrm{A}_{\mathrm{o}} \exp \left(-\left(\mathrm{t}-\mathrm{x}_{\mathrm{o}}\right) * k_{\text {off }}\right)$

eq. 2

where $\mathrm{Y}$ is the observed fluorescence intensity at time $t, \mathrm{Y}_{\mathrm{o}}$ and $\mathrm{A}_{\mathrm{o}}$ are variables, and $k_{\text {off }}$ is the dissociation rate constant. The "dead time" $\mathrm{x}_{0}$ was determined independently [16], and can be estimated from fitting. In our setting, it was determined to be $20 \mathrm{~ms}$.

\section{Chemical Stabilities}

To determine chemical stabilities, approximately $10 \mu \mathrm{M}$ unlabeled or $5 \mu \mathrm{M}$ AEDANS-labeled protein was incubated in a buffer containing $50 \mathrm{mM}$ EPPS, pH 8.0, $500 \mu \mathrm{M}$ EDTA $\left(1 \mathrm{mM} \mathrm{Ca}^{2+}\right.$ or $\left.10 \mathrm{mM} \mathrm{Mg}{ }^{2+}\right)$, and guanidine hydrochloride (Gdn) ranging from 0 to $6 \mathrm{M}$ for at least $6 \mathrm{~h}$. The samples were excited at $295 \mathrm{~nm}$ ( $340 \mathrm{~nm}$ for the labeled proteins), and the wavelengths of their emission were recorded. The maximum emission wavelengths of AEDANS-CaBD and
AEDANS-E99Q/E143Q induced by Gdn were fitted into eq.3 to determine the fraction of unfolded protein $\left(f_{U}\right)$, assuming a two-state unfolding model

$\mathrm{f}_{\mathrm{U}}=\frac{F_{o b s}-F_{N}}{F_{D}-F_{N}}$

where $F_{N}, F_{D}$, and $F_{o b s}$ represent the maximum emission wavelengths in the native state, unfold state, and in the presence of a given concentration of the denaturant ([D]), respectively. Because $\mathrm{F}$ is linearly dependent on the $\mathrm{Gdn}$ concentration in the native and unfolded states, $F_{N}$ and $F_{U}$ were determined from the baselines prior and after the unfolding transition using

$\mathrm{F}_{\mathrm{N}}=\mathrm{m}_{\mathrm{N}}[\mathrm{D}]+\mathrm{Y}_{\mathrm{N}}$

eq. $4 \mathrm{a}$

$F_{D}=m_{D}[D]+Y_{D}$

eq. $4 \mathrm{~b}$

where $m_{N}$ and $m_{D}$ are the slopes, and $Y_{N}$ and $Y_{D}$ are intercepts.

For chemical stability determined by Trp fluorescence, the $\mathrm{f}_{\mathrm{u}}$ was simply calculated as

$\mathrm{f}_{\mathrm{U}}=\frac{\lambda_{o b s}-\lambda_{0 M}}{\lambda_{6 M}-\lambda_{0 M}}$

where the $\lambda_{\text {obs }}$ is the maximum wavelength of the protein at specific concentration of Gdn, $\lambda_{0 \mathrm{M}}$ and $\lambda_{6 \mathrm{M}}$ are the maximum wavelengths of the protein in the absence of Gdn and in the presence of $6 \mathrm{M} \mathrm{Gdn}$, representing the completely folded and unfolded states.

\section{RESULTS AND DISCUSSION}

\section{Effects of Metal Ions on the Fluorescence Spectra of CaBD}

Previously Bánfi et al. had expressed the recombinant CaBD (residues 1-169) of NOX5 in E. coli, in which it was initially expressed as a glutathione S-transferase (GST) fusion protein followed by thrombin cleavage [10]. Since CaBD contains three tryptophan (W9, W12, and W165) and one tyrosine (Y87), it is suitable for a study using fluorometry. It had been demonstrated that its Trp fluorescence intensity was enhanced upon $\mathrm{Ca}^{2+}$ binding. Interestingly, the fluorescence of its half domains, termed as $\mathrm{N}-\mathrm{CaBD}$ (residues 1-78) and C-CaBD (residues 79-169), did not respond $\mathrm{Ca}^{2+}$, and therefore it was concluded that the resulting fluorescence enhancement was only associated with the relative conformational change of the two half domains. To eliminate the cleavage step used in the previous study that limits the amount of purified protein for structural and functional studies, we placed a six-histidine tag at the Nterminus of $\mathrm{CaBD}$ and purified it to be homogeneous. Our approach generated a good amount of purified recombinant protein with typical yields of $10-20 \mathrm{mg}$ per liter culture.

We then characterized our recombinant $\mathrm{CaBD}$ by performing similar experiments using fluorescence spectroscopy except that an excitation wavelength at $295 \mathrm{~nm}$ was used to selectively excite Trp residues. $\mathrm{Ca}^{2+}$ binding to $\mathrm{CaBD}$ enhanced the fluorescence $\sim 40 \%$, as determined by the integration of the spectra (all subsequent cited enhancements were from integration) and the maximum peak was shifted from $340 \mathrm{~nm}$ to $344 \mathrm{~nm}$ (Fig. 1A). The calcium- 
induced fluorescence change indicates that our protein was functionally active, but the enhancement was somewhat lower than the previous report [10]. The reason for this discrepancy is not clear, but it may be due to the difference in the protein constructs such as the different additional $\mathrm{N}$ terminal residues and a longer polypeptide we used (residues 1-184), excitation wavelengths, and/or purification procedures. We also detected significant fluorescence change upon $\mathrm{Mg}^{2+}$ binding though the enhancement was lower $(\sim 10$ $\%)$. The signal leveled off after approximately $600 \mu \mathrm{M}$ of $\mathrm{Mg}^{2+}$, but it is not clear whether all EF-hands were completely occupied at this concentration, mainly due to lack of information regarding the relationship between structural and spectroscopic changes. Therefore, $2 \mathrm{mM} \mathrm{Mg}^{2+}$ was used in our all subsequent experiments except chemical unfolding experiments to ensure saturation. The EF-hands of CaBD appeared to bind specifically to $\mathrm{Ca}^{2+}$ because the addition of $40 \mu \mathrm{M} \mathrm{Ca}^{2+}$ to $\mathrm{Mg}^{2+}$-bound $\mathrm{CaBD}$ quickly converted it to its $\mathrm{Ca}^{2+}$-bound form judged by the different fluorescence profiles of the metal-free and metal-bound forms. This finding is consistent with the previous result showing that $\mathrm{Mg}^{2+}$ does not affect $\mathrm{Ca}^{2+}$ binding to $\mathrm{CaBD}$ [10].

Since the intrinsic fluorescence measurements only reflect the changes near the vicinities of the three Trp residues, it is difficult to differentiate the fluorescence contribution from each individual residue. In order to obtain more specific structural information, we labeled the Cys 107 residue with IAEDANS to generate AEDANS-CaBD. The Cys 107 residue is located between the $3^{\text {rd }}$ EF-loop (residues
88-99) and $4^{\text {th }}$ EF-loop (residues 132-143) in the C-terminal half, and the labeling on this site should serve as a particular probe for the behavior of the C-terminal lobe. $\mathrm{Ca}^{2+}$ and $\mathrm{Mg}^{2+}$ binding to AEDANS-CaBD enhanced the fluorescence intensity by $18 \%$ and $10 \%$, respectively, and their maximum emission wavelengths were shifted from $470 \mathrm{~nm}$ to 466 and $460 \mathrm{~nm}$ for $\mathrm{Mg}^{2+}$ and $\mathrm{Ca}^{2+}$ binding, respectively, which suggest the local environment of AEDANS is more hydrophobic in the $\mathrm{Ca}^{2+}$-bound form than in the $\mathrm{Mg}^{2+}$-bound form (Fig. 1B). In our case, fluorescence spectra of $\mathrm{Mg}^{2+}$ $\mathrm{CaBD}$ were identical in the presence and absence of EGTA, a specific $\mathrm{Ca}^{2+}$ chelating agent, indicating such signal enhancement upon $\mathrm{Mg}^{2+}$ addition was not due to calcium contamination. Despite the fact that such a change can be monitored by fluorescence spectroscopy, the lack of a direct stoichiometric relationship for the amount of $\mathrm{Ca}^{2+}$ or $\mathrm{Mg}^{2+}$ binding that truly affects Trp and AEDANS fluorescence prevents us determining $\mathrm{Ca}^{2+} / \mathrm{Mg}^{2+}$ binding affinity. The increases in Trp and AEDNAS fluorescence caused by $\mathrm{Mg}^{2+}$ binding were smaller than those caused by $\mathrm{Ca}^{2+}$ binding, which indicates the local environments of Trp and Cys107 residues were different among the apo, $\mathrm{Ca}^{2+}-$ and $\mathrm{Mg}^{2+}$ bound forms.

\section{ANS Binding and Stern-Volmer Quenching}

The dye ANS was used to investigate the solventaccessible hydrophobic surface in the apo-, $\mathrm{Ca}^{2+}$ - and $\mathrm{Mg}^{2+}$ bound states (Fig. 2). Similar to the previous result using TNS [10], $\mathrm{Ca}^{2+}$ binding to CaBD caused $\sim 4$ fold increase in ANS fluorescence, but $\mathrm{Mg}^{2+}$ binding to CaBD slightly
A

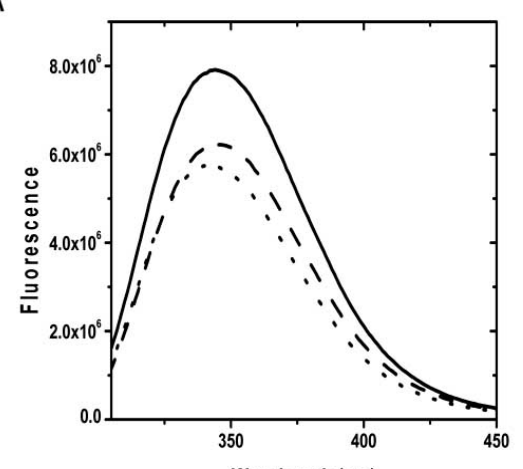

C

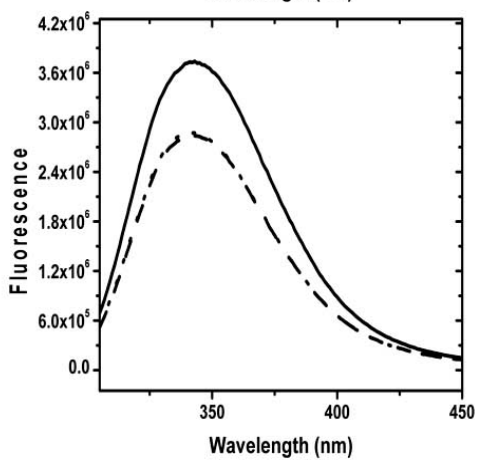

B
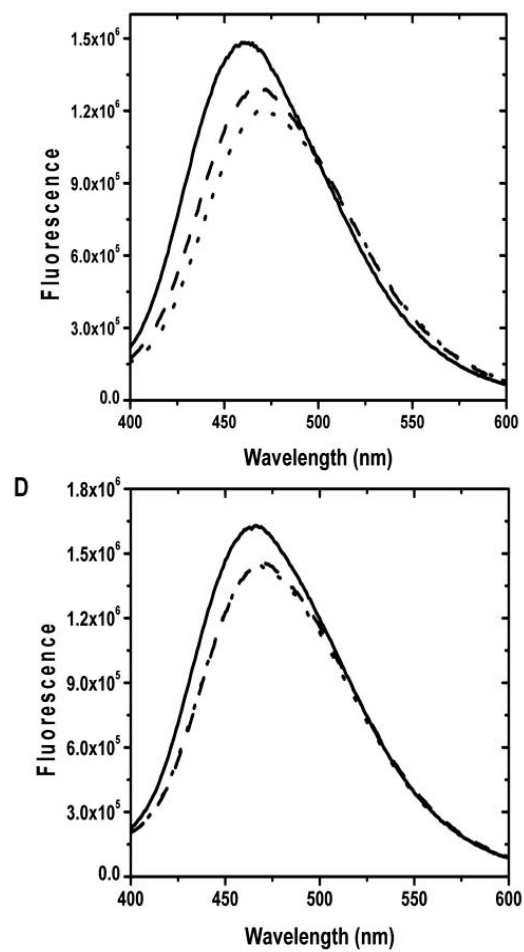

Fig. (1). Steady-state Fluorescence Spectra of CaBD and E99Q/E143Q.

The emission spectra of proteins were recorded at $20{ }^{\circ} \mathrm{C}$ in the presence of $500 \mu \mathrm{M}$ EDTA (dotted line), $2 \mathrm{mM} \mathrm{Mg}^{2+}$ and $1 \mathrm{mM} \mathrm{EGTA} \mathrm{(dash}$ line) and $100 \mu \mathrm{M} \mathrm{Ca}^{2+}$ (solid line). (A) and (B) show Trp and AEDANS fluorescence of CaBD, where (C) and (D) show Trp and AEDANS fluorescence of E99Q/E143Q. 


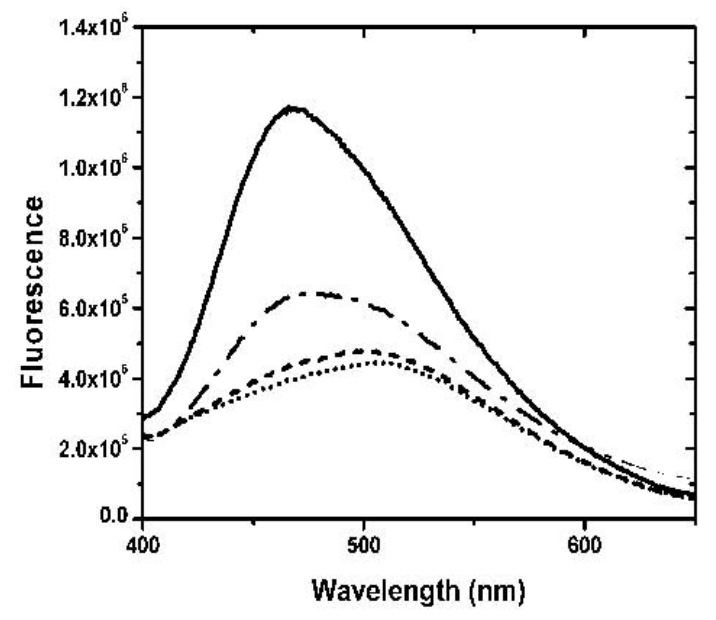

Fig. (2). Hydrophobic Exposures upon Metal Binding.

ANS binding to CaBD was monitored in the presence of $500 \mu \mathrm{M}$ EDTA (dotted line), $2 \mathrm{mM} \mathrm{Mg}^{2+}$ plus $1 \mathrm{mM}$ EGTA (dash line), and $100 \mu \mathrm{M} \mathrm{Ca}^{2+}$ (solid line). ANS binding to E99Q/E143Q in the presence of $100 \mu \mathrm{M} \mathrm{Ca}^{2+}$ is presented as a dash-dotted line.

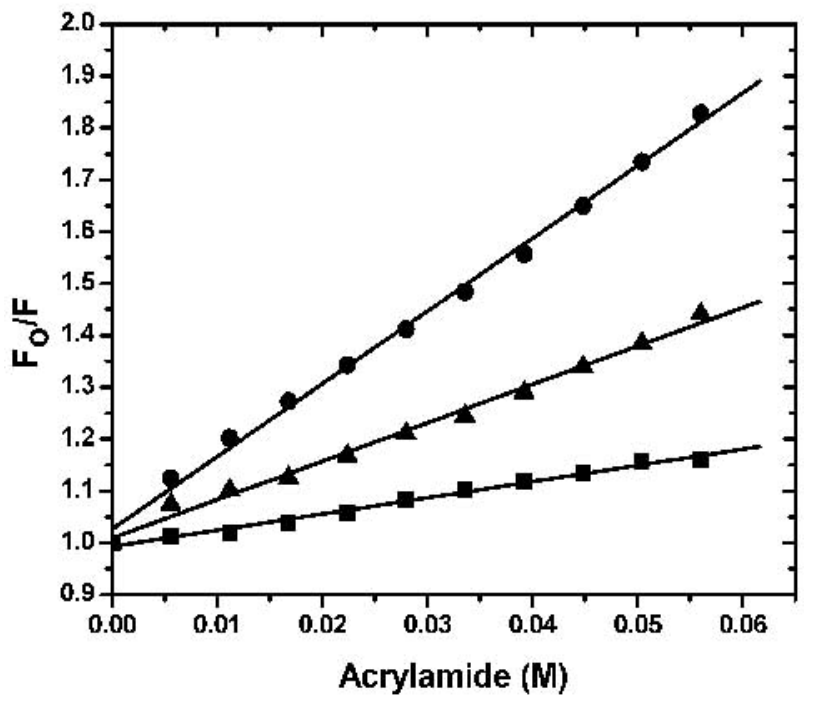

Fig. (3). AEDANS Fluorescence Quenching by Acrylamide.

$2 \mu \mathrm{M}$ AEDANS-CaBD in the presence of $100 \mu \mathrm{M}$ EDTA (square), $2 \mathrm{mM} \mathrm{Mg}^{2+}$ plus $1 \mathrm{mM}$ EGTA (triangle), or $100 \mu \mathrm{M} \mathrm{Ca}^{2+}$ (circle) was titrated with increasing amounts of acrylamide. The standard Stern-Volmer equation was used to fit the data as described in the experimental section and their $\mathrm{K}_{\mathrm{sv}}$ values are shown in Table $\mathbf{1}$.

increased ANS fluorescence. These data indicate that $\mathrm{Mg}^{2+}-$ CaBD has a structure similar to the apo form. To further test this hypothesis, we determined the accessibility of the Trp residues and the AEDANS motif by fluorescence quenching. Fig. (3) shows the Stern-Volmer plots for the acrylamide quenching. Intrinsic fluorescence quenching revealed an upward quenching curve, which was more obvious with high concentration of quencher (data not shown). The upward curves are consistent with ground state heterogeneity and occurrence of dynamic and static quenching, but it is difficult to analyze those effects due to lack of structural information. In order to easily compare Trp accessibility, we only determined the quenching in the low concentrations of acrylamide and fitted the data with a linear quenching equation to obtain the Stern-Volmer quench constant $\left(\mathrm{K}_{\mathrm{sv}}\right)$. The structures of the individual forms can be differentiated by fluorescence quenching: Trp residue(s) were more accessible for quenching in the calcium-bound form with the $\mathrm{K}_{\mathrm{sv}}$ value of $9.49 \mathrm{M}^{-1}$, than the $\mathrm{Mg}^{2+}$-bound form with the $\mathrm{K}_{\mathrm{sv}}$ value of $5.04 \mathrm{M}^{-1}$ and the apo form with the $\mathrm{K}_{\mathrm{sv}}$ value of $5.28 \mathrm{M}^{-1}$ (Table 1). AEDANS fluorescence quenching shows a similar trend, but the $\mathrm{Mg}^{2+}$-bound form appeared to be more sensitive than $\operatorname{Trp}$ quenching. This suggests that $\mathrm{Mg}^{2+}$ binding causes structural changes in the C-terminal half, but the change does not induce exposure of hydrophobic patches for ANS binding or enhance Trp fluorescence quenching. Both intrinsic and extrinsic fluorescence quenching revealed that there is an increase in the exposure of chromophores upon $\mathrm{Ca}^{2+}$ binding, whereas $\mathrm{Mg}^{2+}$ only affects the C-terminal half. It is not clear whether the $\mathrm{N}$-terminal half binds $\mathrm{Mg}^{2+}$ because there is no suitable fluorophore for detection of $\mathrm{Mg}^{2+}$ binding at that half domain.

Table 1. Stern-Volmer Quenching Constants Obtained from Acrylamide Titration

\begin{tabular}{|c|c|c|c|}
\hline \multicolumn{4}{|c|}{$\mathbf{K}_{\text {sv }}\left(\mathbf{M}^{-1}\right)$} \\
\hline Protein & apo & Mg $^{2+}$ & $\mathbf{C a}^{2+}$ \\
\hline \hline CaBD $^{\mathrm{a}}$ & $5.28 \pm 0.50$ & $5.04 \pm 0.29$ & $9.49 \pm 0.41$ \\
\hline E99Q/E143Q $^{\mathrm{a}}$ & $3.01 \pm 0.25$ & $2.92 \pm 0.19$ & $2.95 \pm 0.11$ \\
\hline AEDANS-CaBD $^{\mathrm{b}}$ & $3.02 \pm 0.42$ & $6.40 \pm 0.82$ & $12.01 \pm 1.025$ \\
\hline $\begin{array}{c}\text { AEDANS- } \\
\text { E99Q/E143Q }\end{array}$ & $2.10 \pm 0.21$ & $2.46 \pm 0.32$ & $2.97 \pm 0.26$ \\
\hline
\end{tabular}

${ }^{a}$ The data were obtained by fitting with a linear Stern-Volmer equation.

${ }^{\mathrm{b}}$ The labeled proteins were excited at $340 \mathrm{~nm}$ and their intensities at the maximum emission wavelength were recorded.

\section{Secondary Structures Determined by Circular Dichroism}

The studies using fluorescence spectroscopy suggest significant conformational changes in $\mathrm{CaBD}$ upon $\mathrm{Ca}^{2+}$ binding. To further determine such change, we used $C D$ spectroscopy to monitor the secondary structure content. In the absence of $\mathrm{Ca}^{2+}$, the $\mathrm{CD}$ spectrum shows two negative elliptical peaks near 208 and $222 \mathrm{~nm}$ and one large positive band at $190 \mathrm{~nm}$ (Fig. 4), which are characteristic peaks of proteins containing a dominate $\alpha$-helical secondary structure. However, neither the addition of $\mathrm{Ca}^{2+}$ nor $\mathrm{Mg}^{2+}$ significantly changed the CD signal. These data are similar to the studies showing that the secondary structures of the $\mathrm{CaM}$ superfamily are nearly unaltered by $\mathrm{Ca}^{2+}$ or $\mathrm{Mg}^{2+}$ binding, but that the angle and distances between structural motifs change [17].

\section{Kinetics of Calcium and Magnesium Association and Dissociation}

We used fluorescence spectroscopy coupled with a stopped-flow device to measure the kinetics of the calcium and magnesium association and dissociation of $\mathrm{CaBD}$. To measure calcium association, a solution containing CaBD in the presence of $10 \mu \mathrm{M}$ EDTA was rapid-mixed with an equal volume of a buffer containing $\mathrm{Ca}^{2+}$ ranging from 50 to 200 


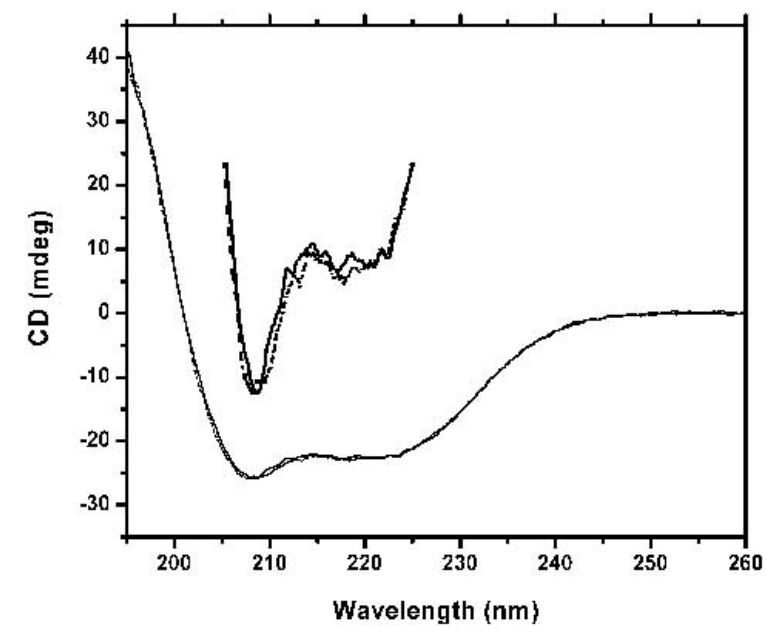

Fig. (4). CD Spectra of CaBD.

Spectra were recorded at $20{ }^{\circ} \mathrm{C}$ in $10 \mathrm{mM}$ Tris, $\mathrm{pH} 7.5$ in the presence of $500 \mu \mathrm{M}$ EDTA (dotted line) and $100 \mu \mathrm{M} \mathrm{Ca}^{2+}$ (solid line).

$\mu \mathrm{M}$. The calcium binding was then monitored by fluorescence. In all cases, the calcium binding was too fast to be detected in our stopped-flow spectrometry (data not shown). This fast binding was confirmed by an experiment including ANS in the reactant syringes in the same condition, in which ANS fluorescence increased and reached the maximum at $75 \mathrm{~ms}$ (data not shown), thus indicating a slow ANS binding after the fast calcium binding. To trigger the calcium dissociation from $\mathrm{CaBD}$, a large excess amount of EDTA was mixed with $\mathrm{Ca}^{2+}-\mathrm{CaBD}$. The kinetic traces obtained fit well to a single-exponential equation (Fig. 5B) and the dissociation rate constant $\left(k_{\text {off }}\right)$ was determined to be $4.5 \pm 0.3 \mathrm{~s}^{-1}$ (mean $\left.\pm \mathrm{SD}, \mathrm{n}=5\right)$. The measured kinetic trace was identical to the experiment using AEDANS-CaBD performed in the same condition, indicating that dyemodification did not impair calcium binding, or at least calcium dissociation. However, the amplitude of the fluorescence decay was approximately 55 - 65\% of total Trp or AEDANS intensity changes (i.e. difference between the $\mathrm{Ca}^{2+}$ - and apo-CaBD), in which the initial intensity for the slow decay was estimated by extrapolating the fitted curve to the time before mixing (i.e. $-20 \mathrm{~ms}$ ), thus implying that there was a non-detectable fast decay. Since AEDANS was labeled specifically in the C-terminal half, it is reasonable to conclude that the slow phase represents the calcium dissociation from the $\mathrm{C}$-terminal half, whereas the fast phase is associated with calcium dissociation from the N-terminal half, in which the cys107-labeled AEDANS is able to sense such a change. To test this hypothesis, we generated a double mutant, E99Q/E143Q, in which the calcium binding sites in the $3^{\text {rd }}$ and $4^{\text {th }}$ EF-hand motifs were removed. We changed the most frequently occurring negative residue, glutamate, at position $12(-Z)$ to glutamine in its canonical EF-hand motifs because several calcium binding proteins demonstrate that such mutation impairs the calcium binding. Such mutational changes were expected to have minimal overall alternation on protein structure [18]. The mutant's partial inability to bind $\mathrm{Ca}^{2+}$ was proved by fluorescence quenching in which its $\mathrm{K}_{\mathrm{sv}}$ values were almost identical in all states (Table $\mathbf{1}$ ), and by the chemical stability discussed below (Fig. 6). Using the unlabeled and labeled E99Q/E143Q, the slow fluorescence decay previously observed in the wild type CaBD disappeared, displaying only a non-detectable fast fluorescence decay (Fig. 5A). Using the dissociation constant for the C-terminal half, $\mathrm{K}_{\mathrm{d}, \mathrm{C}}=4 \mu \mathrm{M}$ and the equation $\mathrm{K}_{\mathrm{d}, \mathrm{C}}=k_{\mathrm{off}, \mathrm{C}} / k_{\mathrm{on}, \mathrm{C}}$, the association rate constant $\left(k_{\mathrm{on}, \mathrm{C}}\right)$ is calculated to be $1.1 \times 10^{6} \mathrm{M}^{-1} \mathrm{~s}^{-1}$. If we assume that the fast decay is within the dead time (i.e. $20 \mathrm{~ms}$ ), the dissociation rate constant for the $\mathrm{N}$-terminal half, $k_{\mathrm{off}, \mathrm{N}}$, is estimated to be $>300 \mathrm{~s}^{-1}$, therefore giving $k_{\mathrm{on}, \mathrm{N}}>1.5 \times 10^{7} \mathrm{M}^{-1} \mathrm{~s}^{-1}$ using $\mathrm{K}_{\mathrm{d}, \mathrm{N}}$ $=20 \mu \mathrm{M}$. The lower $\mathrm{K}_{\mathrm{d}}$ value for $\mathrm{Ca}^{2+}$ binding to the $\mathrm{N}$ terminal half is mainly from its fast calcium dissociation. The data obtained from the previous study examining binding affinity [10] and our kinetics on CaBD is very similar to $\mathrm{CaM}$, in which its C-terminal half was shown to have a tighter binding affinity and a slower calcium dissociation [19].

\section{A}
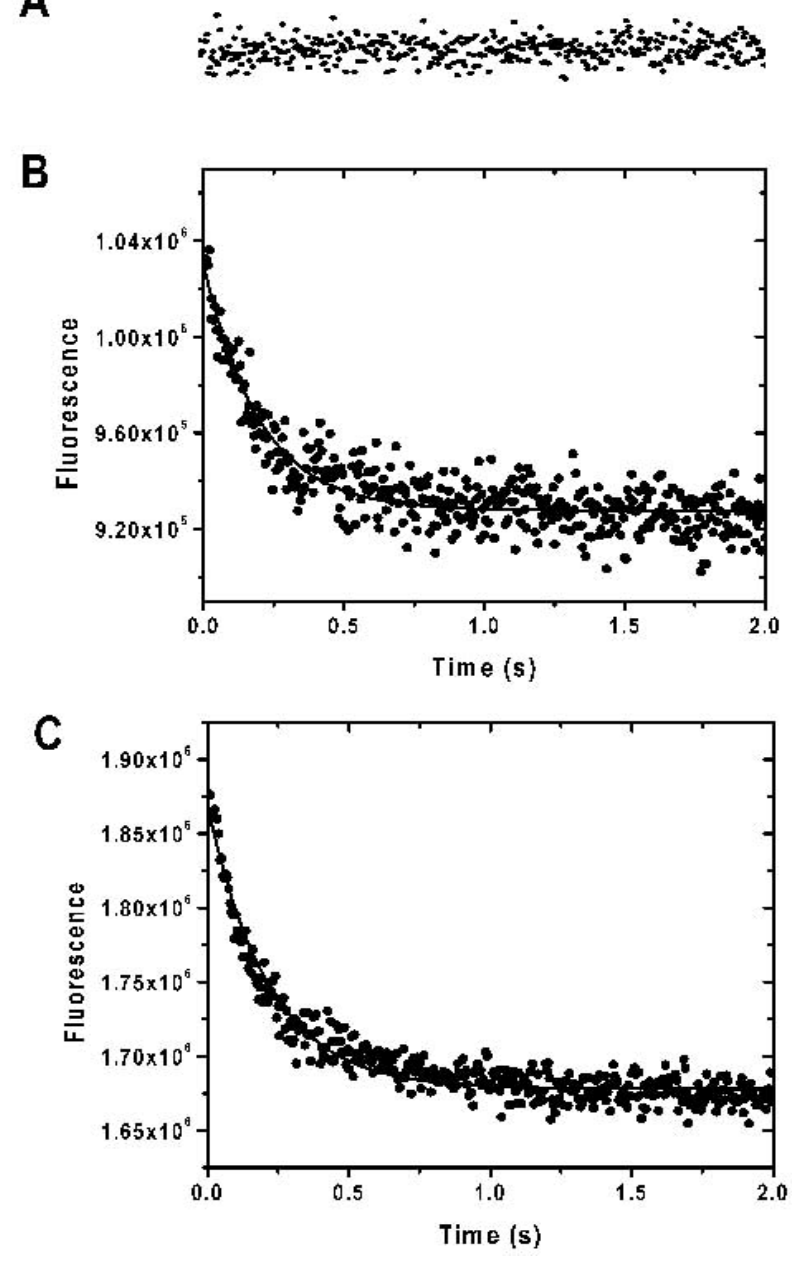

Fig. (5). Kinetics of Metal Dissociation.

$\mathrm{Ca}^{2+}$-bound protein was quick-mixed with a solution containing large excess of EDTA and its fluorescent decay at $460 \mathrm{~nm}$ was recorded with the excitation wavelengths of $340 \mathrm{~nm}$. (A) Shows the kinetic trace of $\mathrm{Ca}^{2+}$ dissociation from AEDANS-E99Q/E143Q, where $(\mathbf{B})$ and $(\mathbf{C})$ show the kinetics of $\mathrm{Ca}^{2+}$ and $\mathrm{Mg}^{2+}$ dissociation from AEDANS-CaBD. The traces are representative of four to six independent experiments each.

While the decay of Trp fluorescence can be easily explained due to the relative changes of the two half 
A

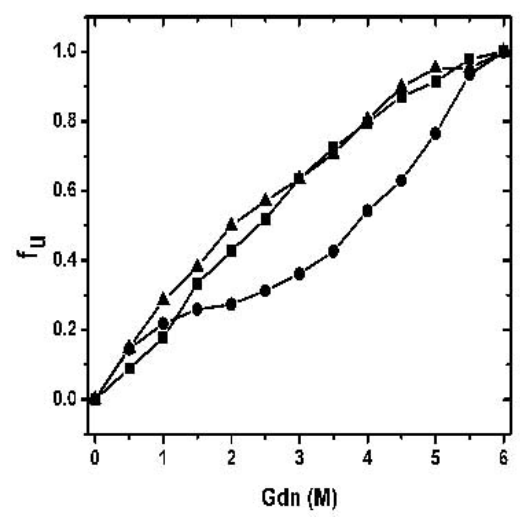

B

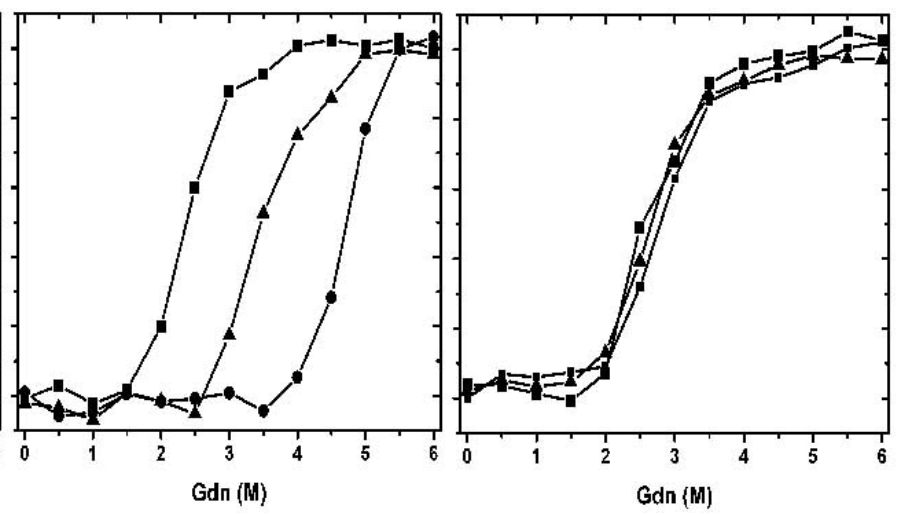

Fig. (6). Chemical Stabilities of CaBD and E99Q/E143Q. Proteins were incubated at different concentrations of Gdn, and their maximum wavelengths were recorded. The percentage of unfolding was calculated as described in the experimental section. (A) shows the chemical unfolding of $\mathrm{CaBD}$ in the presence of $500 \mu \mathrm{M}$ EDTA (square), $10 \mathrm{mM} \mathrm{Mg}^{2+}$ (triangle), and $1 \mathrm{mM} \mathrm{Ca}^{2+}$ (circle). (B) and (C) show the chemical unfolding of AEDANS-CaBD and AEDANS-E99Q/E143Q in the same condition. The curves are the average of three independent experiments each.

domains, the decrease in AEDANS fluorescence, implied in the first calcium dissociation ( $40 \%$ of amplitude), does suggest a significant interaction between the dye and the Nterminal half, possibly through spatial contact and/or the interdomain link. This argument was supported by the fact that the fluorescence spectrum of E99Q/E143Q showed that this mutant still responded to $\mathrm{Ca}^{2+}$ binding with 28 and $9 \%$ enhancements (40 and $18 \%$ for the wild type) for Trp and AEDANS fluorescence, respectively (Fig. 1C \& D). The intrinsic fluorescence change for this mutant might be due to the relative change of two rigid halves, i.e. $\mathrm{Ca}^{2+}-\mathrm{N}-\mathrm{CaND}$ and apo-C-CaBD, by which the interface formed through such interaction maintains a weaker ANS binding (Fig. 2). Such an explanation could not be simply applied to AEDANS-E99Q/E143Q. It has been seen that similar mutations on the $1^{\text {st }}$ or $2^{\text {nd }} \mathrm{EF}$-hands in the N-half domain of $\mathrm{CaM}$ alter structure, and thus fluorescence, resulting in $\mathrm{Ca}^{2+}-$ binding to the C-terminal half domain of $\mathrm{CaM}$, but not $\mathrm{Ca}^{2+}$ binding itself [20]. Furthermore, the possibility of the Cterminal half of this mutant still retaining calcium binding capacity in our experimental condition was eliminated because same mutation on C-CaBD (residues 79-184) resulted in the losing of AEDANS fluorescence response upon $\mathrm{Ca}^{2+}$ binding (unpublished results). Therefore, the calcium binding strengths of the $\mathrm{N}$-terminal half and the $\mathrm{C}$ terminal half are independent as reported previously [10], but their spectroscopic behaviors and thus their structures, appear not to be completely independent. Due to cross communication between the two half domains, our results also raise the question of whether calcium binding within and between the half domains is non-cooperative as previously reported [10].

The kinetics of $\mathrm{Mg}^{2+}$ association was very similar to that of $\mathrm{Ca}^{2+}$. The $\mathrm{Mg}^{2+}$ association was too fast to be detected. The dissociation of $\mathrm{Mg}^{2+}$ triggered by EDTA addition was only observed using AEDANS-CaBD (Fig. 5C). The dissociation rate constant was determined to be $6.65 \pm 1.02 \mathrm{~s}^{-1}$. The amplitude of such decay was identical to the intensity change determined from the steady states, which suggests that this $\mathrm{Mg}^{2+}$ dissociation is from the $\mathrm{C}$-terminal lobe. This conclusion is supported by the fact that AEDANSE99Q/E143Q did not respond to $\mathrm{Mg}^{2+}$ even at very high concentration of $\mathrm{Mg}^{2+}$. Interestingly, the $\mathrm{Mg}^{2+}$ dissociation from $\mathrm{CaBD}$ was too fast to be detected by Trp fluorescence.

\section{Chemical Stabilities of CaBD and Mutant}

Since the data from the previous result indicates structural independence of the $\mathrm{N}$ - and $\mathrm{C}$-terminal halves, the stability of the individual domains may be different in relation to their thermodynamics and kinetics. We therefore performed chemical unfolding induced by guanidine hydrochloride (Gdn). Fig. (6A) shows a plot of the fractions of unfolded protein as a function of Gdn concentrations. The unfolding of $\mathrm{CaBD}$ monitored by intrinsic fluorescence was not a two-state unfolding model. This is consistent with the fact that the three Trp residues are near the peptide ends where structures tend not to be compact. In the presence of $\mathrm{Ca}^{2+}$, the overall stability was enhanced. There were two obvious transitions at $\sim 1$ and $4.5 \mathrm{M}$ Gdn with an intermediate at 2-3 M Gdn. The calcium-bound $\mathrm{CaBD}$ is substantially more stable than the apo form, and the result agrees with the prediction from the theory of ligand binding [21]. Unfortunately, there is no constructive information that can be gathered from intrinsic fluorescence. To acquire specific structural stability, the same experiment using the cys107-labeled $\mathrm{CaBD}$ was conducted. Increasing Gdn concentration resulted in red shift in wavelengths from 470 to $496 \mathrm{~nm}$ in the absence of $\mathrm{Ca}^{2+}$ (data not shown); the unfolding curve, corrected for denaturant effects, appeared to be a two-state model. Fig. (6B and $\mathbf{6 C}$ ) show a plot of the fraction of unfolded protein as a function of denaturant, and the parameter $\mathrm{C}_{\mathrm{m}}$ was determined at the concentration of Gdn where $50 \%$ of the protein was induced unfolded. The unfolding monitored by the extrinsic fluorescence gave the $\mathrm{C}_{\mathrm{m}}$ values approximately $2.5 \mathrm{M}$ and $4.7 \mathrm{M}$ in the absence and presence of $\mathrm{Ca}^{2+}$, respectively; the latter being consistent with the second transition obtained from intrinsic fluorescence. The data also indicated that the $\mathrm{C}_{\mathrm{m}}$ values of the apo forms of $\mathrm{N}$-terminal and $\mathrm{C}$-terminal halves were near $2.5 \mathrm{M}$. Ca ${ }^{2+}$ binding most likely increases the stability of the 
C-terminal half, but not the N-terminal half. This conclusion was supported by using AEDANS-E99Q/E143Q. The unfolding curves were identical in the presence of EDTA, $\mathrm{Mg}^{2+}$, and $\mathrm{Ca}^{2}$, consistent with our previous fluorescence quenching result showing inability of calcium binding in the C-terminal half. The unfolding study of $\mathrm{Ca}^{2+}$-bound AEDANS-E99Q/E143Q also suggests that the $C_{m}$ value for $\mathrm{Ca}^{2+}$-bound $\mathrm{N}$-terminal half is $\sim 2.5 \mathrm{M}$. Interestingly, $\mathrm{Mg}^{2+}$ appeared to stabilize $\mathrm{CaBD}$, more specifically the C-terminal half. This unfolding is concentration-dependent (data not shown) because lowering $\mathrm{Ca}^{2+}$ or $\mathrm{Mg}^{2+}$ concentration destabilizes $\mathrm{CaBD}$ as seen in CaM [21]. It appears that the domain that has a higher calcium binding affinity has a higher degree of stability. This is seen for the C-terminal half, in which its higher chemical stability is due to a higher unfolding free energy difference $\left(\Delta \mathrm{G}_{\mathrm{NU}}\right)$ between the apo and calcium-bound states. In contrast, the N-terminal half domain has free energies which are comparable in apo and calcium-bound forms, thus lowering $\Delta \mathrm{G}_{\mathrm{NU}}$. More thorough unfolding studies with the individual halves using appropriate labeling or other techniques will further determine their free energy difference and cooperative unfolding transition for each domain. Our result indicates that the correlation between binding affinity and domain stability for $\mathrm{CaBD}$ agrees with other calcium binding proteins [20, 22].

\section{CONCLUSION}

$\mathrm{Ca}^{2+}$-induced electron transfer controlled by the CaBDflavoprotein interaction in NOX5 is very important in the regulation of its superoxide production. In fact, we found that the heme reduction $\left(\mathrm{Fe}^{3+}\right.$ to $\mathrm{Fe}^{2+}$ ) of NOX5 was only observed in the presence of $\mathrm{Ca}^{2+}$ in an anaerobic condition (Wei and Stuehr, unpublished result), suggesting that this domain-domain interaction mediates electron transfer from NADPH to FAD and/or FAD to heme. Previously Bánfi et al. had generated GST-fused $\mathrm{CaBD}$ and demonstrated its conformational change upon $\mathrm{Ca}^{2+}$ binding mainly by Trp and TNS fluorescence [10]. We extended such studies by characterizing $\mathrm{CaBD}$ and the E99Q/E143Q mutant. Our finding is similar to what they reported on Trp fluorescence enhancement and hydrophobic patch formation upon $\mathrm{Ca}^{2+}$ binding. However, we investigated more thoroughly on such conformational change by including acrylamide quenching, chemical stability, and secondary structure change by $\mathrm{CD}$ spectroscopy. The kinetics of $\mathrm{Ca}^{2+}$ association and dissociation was studied by stopped-flow spectrometry. Our data indicated that the $\mathrm{C}$-terminal half of $\mathrm{CaBD}$ has a higher $\mathrm{Ca}^{2+}$ binding affinity, a higher chemical stability, and a slow $\mathrm{Ca}^{2+}$ dissociation. By using site-specific AEDANS labeled proteins, our data also suggest the $\mathrm{N}$ - and $\mathrm{C}$-terminal halves of $\mathrm{CaBD}$ are structurally dependent.

Furthermore, $\mathrm{Mg}^{2+}$ binding to $\mathrm{CaBD}$ was observed in the intrinsic and extrinsic fluorescence. Whether $\mathrm{Mg}^{2+}-\mathrm{CaBD}$ is of any biological importance is not known. But like other EF-hands containing proteins, $\mathrm{Mg}^{2+}$ may play a role in a cellular condition, where its concentration is $0.5-2 \mathrm{mM}$ and $\mathrm{Mg}^{2+}$ may either occupy two or all four calcium binding sites. The exchange of $\mathrm{Ca}^{2+}$ for $\mathrm{Mg}^{2+}$ is likely to limit the association and dissociation of the calcium ions [23]. Indeed, the rate of $\mathrm{Mg}^{2+}$ dissociation for CaBD was comparable to calcium dissociation. In resting cells, NOX5 appears to bind
$\mathrm{Mg}^{2+}$ and its structure mostly resembles the apo form. As calcium concentration elevates upon cell stimulation, the rate of $\mathrm{Ca}^{2+}$ association to $\mathrm{CaBD}$ is compromised by a slow dissociation of the bound $\mathrm{Mg}^{2+}$ ions. The chemical unfolding study suggested that such $\mathrm{Mg}^{2+}$ binding enhances the stability of $\mathrm{CaBD}$ in resting cells. $\mathrm{Mg}^{2+}$ binding only alters the local conformational changes, particularly near the $\mathrm{C}$ terminal end, while $\mathrm{Ca}^{2+}$ binding leads to global conformational changes of the two half domains.

Recent studies indicate that NOX5's $\mathrm{Ca}^{2+}$ sensitivity is enhanced when its flavoprotein domain interacts with $\mathrm{CaM}$ [13] or is phosphorylated at its Thr494 and Ser498 residues [14]. Since the activation still relies on $\mathrm{Ca}^{2+}$ binding, exactly how the structural change in the C-terminal flavoprotein end induced by the above mechanisms propagates to $\mathrm{CaBD}$ remains to be studied further. Therefore, structural information about $\mathrm{CaBD}$ gathered from spectroscopy is important for investigation of such structural communication.

\section{ACKNOWLEDGEMENTS}

We thank Dr. Carl Frieden at Washington University at St. Louis for allowing us to use his CD spectrometer. We thank the financial support from Cottrell College Science Awards (CCSA) of Research Corporation and Summer Research Fellowships (SRF) from Southern Illinois University Edwardsville (SIU Edwardsville) to $\mathrm{CCW}$; Research Grants for Graduate Students (RGGS) from SIU Edwardsville to LQC and TJ; and Undergraduate Research Academy (URA) from SIU Edwardsville to NM, LH, and KL. We also thank Kristen Wetherell, Nicole Reynolds, and Tiffany Williams (SIU Edwardsville) and Anjali Shekar (O'Fallon High School, supported by 2009 Summer Students and Teachers As Research Scientists (STARS)) for helping with protein expression and purification.

\section{SUPPLEMENTARY MATERIAL}

Supplementary material is available on the publishers Web site along with the published article. 


\section{REFERENCES}

[1] Bedard, K.; Krause, K. H. The NOX family of ROS-generating NADPH oxidases: physiology and pathophysiology. Physiol. Rev., 2007, 87, 245-313.

[2] Lambeth, J. D.; Kawahara, T.; Diebold, B. Regulation of Nox and Duox enzymatic activity and expression. Free Radic. Biol. Med., 2007, 43, 319-331.

[3] Cheng, G.; Cao, Z.; Xu, X.; van Meir, E. G.; Lambeth, J. D. Homologs of gp91phox: cloning and tissue expression of Nox3, Nox4, and Nox5. Gene, 2001, 269, 131-140.

[4] Nauseef, W. M. Assembly of the phagocyte NADPH oxidase. Histochem. Cell Biol., 2004, 122, 277-291.

[5] Van Heerebeek, L.; Meischl, C.; Stooker, W.; Meijer, C. J.; Niessen, H. W.; Roos, D. NADPH oxidase(s): new source(s) of reactive oxygen species in the vascular system? J. Clin. Pathol., 2002, 55, 561-568.

[6] Cave, A. Selective targeting of NADPH oxidase for cardiovascular protection. Curr. Opin. Pharmacol., 2009, 9, 208-213.

[7] Nistala, R.; Whaley-Connell, A.; Sowers, J. R. Redox control of renal function and hypertension. Antioxid. Redox Signal., 2008, 10, 2047-89.

[8] Sorce, S.; Krause, K. H. NOX enzymes in the central nervous system: from signaling to disease. Antioxid. Redox Signal., 2009, 11, 2481-2504.

[9] Banfi, B.; Molnar, G.; Maturana, A.; Steger, K.; Hegedus, B.; Demaurex, N.; Krause, K.H. A Ca(2+)-activated NADPH oxidase in testis, spleen, and lymph nodes. J. Biol. Chem., 2001, 276, 37594-37601.

[10] Banfi, B.; Tirone, F.; Durussel, I.; Knisz, J.; Moskwa, P.; Molnar, G. Z.; Krause, K. H.; Cox, J. A. Mechanism of $\mathrm{Ca}^{2+}$ activation of the NADPH oxidase 5 (NOX5). J. Biol. Chem., 2004, 279, 1858318591.

[11] Armstrong, J. S.; Bivalacqua, T. J.; Chamulitrat, W.; Sikka, S.; Hellstrom, W. J. A comparison of the NADPH oxidase in human sperm and white blood cells. Int. J. Androl., 2002, 25, 223-229.
[12] Cross, A.R.; Segal, A.W. The NADPH oxidase of professional phagocytes--prototype of the NOX electron transport chain systems. Biochim. Biophys. Acta, 2004, 1657, 1-22.

[13] Tirone, F.; Cox, J. A. NADPH oxidase 5 (NOX5) interacts with and is regulated by calmodulin. FEBS Lett., 2007, 581, 1202-1208.

[14] Jagnandan, D.; Church, J. E.; Banfi, B.; Stuehr, D. J.; Marrero, M. B.; Fulton, D. J. Novel mechanism of activation of NADPH oxidase 5. calcium sensitization via phosphorylation. J. Biol. Chem., 2007, 282, 6494-6507.

[15] Gopalakrishna, R.; Anderson, W.B. Ca2+-induced hydrophobic site on calmodulin: application for purification of calmodulin by phenyl-Sepharose affinity chromatography. Biochem. Biophys. Res. Commun., 1982, 104, 830-836.

[16] Peterman, B.F. Measurement of the dead time of a fluorescence stopped-flow instrument. Anal. Biochem., 1979, 93, 442-444.

[17] Skelton, N.J.; Kordel, J.; Akke, M.; Forsen, S.; Chazin, W.J. Signal transduction versus buffering activity in $\mathrm{Ca}(2+)$-binding proteins. Nat. Struct. Biol., 1994, 1, 239-245.

[18] Beckingham, K. Use of site-directed mutations in the individual $\mathrm{Ca} 2(+)$-binding sites of calmodulin to examine $\mathrm{Ca} 2(+)$-induced conformational changes. J. Biol. Chem., 1991, 266, 6027-6030.

[19] Brown, S. E.; Martin, S. R.; Bayley, P. M., Kinetic control of the dissociation pathway of calmodulin-peptide complexes. J. Biol. Chem., 1997, 272, 3389-3397.

[20] Zhang, M.; Tanaka, T.; Ikura, M. Calcium-induced conformational transition revealed by the solution structure of apo calmodulin. Nat. Struct. Biol., 1995, 2, 758-767.

[21] Masino, L.; Martin, S.R.; Bayley, P.M. Ligand binding and thermodynamic stability of a multidomain protein, calmodulin. Protein Sci., 2000, 9, 1519-1529.

[22] Fredricksen, R.S.; Swenson, C.A. Relationship between stability and function for isolated domains of troponin C. Biochemistry, 1996, 35, 14012-14026.

[23] Gifford, J.L.; Walsh, M.P.; Vogel, H.J. Structures and metal-ionbinding properties of the $\mathrm{Ca}^{2+}$-binding helix-loop-helix EF-hand motifs. Biochem. J., 2007, 405, 199-221.

(C) Wei et al.; Licensee Bentham Open.

This is an open access article licensed under the terms of the Creative Commons Attribution Non-Commercial License (http://creativecommons.org/licenses/by-nc/3.0/) which permits unrestricted, non-commercial use, distribution and reproduction in any medium, provided the work is properly cited. 